\title{
Trabajo y subjetividad: reflexiones a partir de la experiencia de enfrentar el COVID-19 en el Sistema Único de Salud de Brasil
}

\author{
Work and subjectivity: reflections on experiences \\ dealing with COVID-19 in the Brazilian Unified Health \\ System
}

'Doctora en Salud Pública. Profesora asociada, Departamento de Política, Gestión y Salud, Faculdade de Saúde Pública, Universidade de São Paulo, São Paulo, Brasil. $\bowtie$ (iD)
RESUMEN Este artículo busca problematizar la relación trabajo y subjetividad a partir de una reflexión sobre experiencias y modos de enfrentar la epidemia de SARS-Cov 2 (COVID-19) en el Sistema Único de Salud (SUS) de San Pablo, Brasil. Para eso se realiza una contextualización de la política brasileña y del SUS, rescatando los modos de hacer política en salud. Luego, se presentan los modos de enfrentar la pandemia en el SUS sobre la base de diversas rondas de conversaciones con las y los trabajadores de la salud acerca de lo vivido en la pandemia y su enfrentamiento político, sobre vivencias en el primer nivel de atención, en salud mental, y con los movimientos sociales, cuyo registro está disponible en Youtube. Sobre estos registros, se analizan elementos conceptuales que procuran ampliar las nociones en torno al trabajo en salud, las políticas, las prácticas en salud y los procesos de subjetivación, destacando aprendizajes y retos hacia el futuro.

PALABRAS CLAVES Sistema Único de Salud; Política de Salud; Pandemia por el Nuevo Coronavirus 2019; Trabajo; Brasil.

\begin{abstract}
This article presents a critical analysis of the relationship between work and subjectivity, based on reflections regarding experiences of dealing with the SARS-CoV-2 (COVID-19) epidemic in the Unified Health System (SUS) in Sao Paulo, Brazil. In order to do so, context is first provided regarding Brazilian policy and the SUS, drawing attention to different modes of health policy formulation. The ways in which the challenges of the pandemic were dealt with in the SUS are then presented, through an examination of material from panel discussions held with healthcare workers - which are publicly available on Youtube - regarding what they have lived through during the pandemic and the political conflicts they have encountered, as well as their lived experiences with the primary level of care, with mental health, and with social movements. This material is analyzed vis-à-vis conceptual elements that seek to expand upon notions of healthcare work, policies and practices in health care, and subjectification processes, shedding light on lessons that have emerged and on future challenges.
\end{abstract}

KEY WORDS Unified Health System; Health Policy; 2019-nCoV Pandemic; Work; Brazil. 


\section{INTRODUCCIÓN Y ASPECTOS METODOLÓGICOS}

Este artículo busca problematizar la relación trabajo y subjetividad, a partir de reflexionar sobre las experiencias y los modos de enfrentar la epidemia de SARS-Cov 2 (COVID-19) en el Sistema Único de Salud (SUS), para lo cual se realiza una contextualización de la política brasileña y del SUS, que rescata los modos de hacer política en salud. Luego se presentan los modos de enfrentar la pandemia en el SUS y los elementos conceptuales que procuran ampliar las nociones en torno al trabajo en salud, las políticas, las prácticas en salud y los procesos de subjetivación.

La recopilación de los modos de enfrentar el COVID-19 en el SUS se produjo a partir de experiencias compartidas durante la pandemia de un modo informal, en algunas regiones del municipio de San Pablo, en municipios del gran San Pablo y del interior paulista, en reuniones del grupo de investigación de Micropolítica y Salud de la Facultad de Salud Pública de la Universidade de São Paulo. Las y los trabajadores de esos espacios integran el grupo de investigación o se unieron para compartir y reflexionar sobre lo que estaban viviendo, en el marco de una oferta de soporte que el grupo hizo y hace, y varios aceptaron y aceptan. Se trata de un proceso informal, que no es característico de un campo de investigación, sino que es un proceso colectivo vivo para problematizar las experiencias vividas.

Esta es una de las maneras que implementó nuestro grupo de investigación para apoyar el trabajo en diferentes espacios del SUS durante la pandemia, una modalidad que entendemos como educación permanente en salud: aprendizaje de la experiencia, en espacios formales o informales, con o sin apoyo externo ${ }^{(1,2)}$. En nuestro caso, se trata de una oferta de espacio colectivo, que posibilitó el debate y la reflexión sobre diversas experiencias. Tuvimos muchos días de conversación: sobre lo vivido en la pandemia y su enfrentamiento político, sobre vivencias en unidades básicas de salud, en salud mental, y en los movimientos sociales.
Conversaciones que producen visibilidad, decibilidad, pero también producen incomodidad y otras expresiones más.

El registro de las diversas rondas de conversaciones virtuales, que contribuyeron a la recopilación de experiencias de trabajadores y gestores de la salud de algunas regiones del estado de San Pablo, de Paraná y de Rio de Janeiro, está disponible en Youtube y los enlaces han sido citados a lo largo del texto. Parte de esas experiencias también fueron objeto de reflexión en otro artículo titulado "La crisis como potencia: los cuidados de proximidad y la epidemia de COVID-19"(3) publicado a inicios de 2021, cuya autoría comparto.

\section{UN POCO DE CONTEXTO SOBRE EL SISTEMA ÚNICO DE SALUD}

La experiencia política brasileña en el enfrentamiento de las desigualdades sociales y el rico movimiento social de conquista de la salud como derecho, como también el singular, intenso y tenso proceso de construcción del SUS han sido objeto de amplias reflexiones y ricos aprendizajes en el campo de la salud colectiva, discutidos en muchos países de América Latina e incluso de otras latitudes. Muchos aprendizajes, problemas, problematizaciones y ufanismos ${ }^{(4,5)}$.

Sin embargo, desde 2013 se delineó un escenario político muy desfavorable para la democracia y las políticas sociales en Brasil. En primer lugar, por el progresivo aislamiento político de la Presidencia de la República y por la crisis recesiva iniciada aún en el gobierno Dilma Rousseff, seguida por el golpe de Estado que implicó la separación arbitraria de su cargo por parte del Congreso Nacional. A continuación, señalo algunos elementos de la coyuntura de la salud, que resultan significativos para nuestro debate.

\section{Financiamiento}

El gobierno de Michel Temer implementó una política de austeridad fiscal, que dio inicio a 
un proceso de destrucción de las políticas públicas y de vaciamiento del papel del Estado en la promoción y defensa de la vida y en la reducción de las desigualdades. Uno de los elementos fundamentales de ese movimiento fue la aprobación de la Enmienda Constitucional No. 95, también conocida como "Enmienda Constitucional del Techo de los Gastos Públicos", que modificó la Constitución brasileña de 1988 para instituir un nuevo régimen fiscal. Esta reforma estableció un límite al crecimiento de los gastos del gobierno brasileño, que alcanzó a los tres poderes, además del Ministerio Público de la Unión y de la Defensoría Pública de la Unión ${ }^{(6)}$.

La inversión y el gasto públicos quedaron limitados a los mismos valores otorgados el año anterior, ajustados a la inflación medida por el Índice Nacional de Precios al Consumidor Amplio (IPCA). La medida tiene una validad inicialmente prevista para un período de 20 años ${ }^{(6)}$.

Las pérdidas acumuladas del financiamiento federal en salud, entre 2018 y 2019 , fueron del orden de los $\mathrm{R} \$ 30.000$ millones de reales ${ }^{(7)}$. Entre 2017 y 2021 (considerando la propuesta presupuestaria actual), el valor per cápita aplicado en salud descendió de $R \$ 594$ reales a $R \$ 535$, deflación producida por el IPCA de 2019, que significó una caída del $10 \%$ del presupuesto del sector. La programación presupuestaria de $R \$ 123.800$ millones de reales para las acciones y servicios públicos de salud, con el piso congelado, no destinó ni un centavo para los gastos dirigidos directamente a enfrentar el COVID-19 ${ }^{(8)}$.

\section{Políticas de salud: tentativas de desmonte y empobrecimiento}

En este contexto, se iniciaron ataques a dos de las políticas más significativas del SUS: la política de salud mental y la de atención básica. Atención básica y APS son conceptos en disputa. La construcción del cuidado interprofesional, contextualizado, basado en un concepto ampliado de salud, en continuidad con otros servicios de base territorial, se distingue de la APS y no se limita al primer nivel de atención ${ }^{(9)}$.

La política de salud mental brasileña, construida de modo ejemplarmente participativo y compartido, con un movimiento social activo, que incluye trabajadores de la salud, usuarios de los servicios de salud mental y sus familiares, marcó la construcción de una política basada en un concepto ampliado de salud y la institución de una red sustitutiva y de prácticas de cuidados en libertad, en intensa disputa de valores y prácticas con el mercado, la biomedicina y la lógica manicomial. Así, se había logrado desactivar progresivamente los hospitales psiquiátricos para ser sustituidos por redes de atención psicosocial. Por el contrario, las recientes políticas incorporaron los hospitales psiquiátricos a la red de atención y ampliaron su financiamiento y el de las comunidades terapéuticas que adoptaran prácticas de confinamiento y punición, uso intensivo de drogas psiquiátricas y abandono de las prácticas de reducción de daños ${ }^{(10)}$.

En la política nacional de atención básica, la más capilar de todas las políticas de salud del país, se eliminó el financiamiento universal per cápita (todos los municipios recibían recursos proporcionales al número de habitantes, independientemente de la prestación de servicios), se desfinanció a los equipos multiprofesionales, el trabajo territorial y las acciones colectivas de salud. Un ataque muy grave a las principales apuestas de la atención básica, de atención integral con base territorial y al concepto ampliado de salud, acercándose a un diseño con propuestas limitadas de la atención primaria de la salud, centrada en el médico y en las acciones clínicas individuales ${ }^{(11)}$.

Generar resistencia a estos ataques exige tanto el ejercicio ampliado del papel productor de políticas en el ámbito estadual y, sobre todo, municipal, como el reconocimiento de que las políticas están en permanente disputa que se efectúa, también, en el trabajo cotidiano en salud, que es atravesado por múltiples fuerzas y proyectos en disputa ${ }^{(12)}$. El contexto político, sin embargo, ha sumado más y más limitaciones, como veremos a continuación. 


\section{Los modos de hacer política}

En 2018, la elección del presidente de extrema-derecha agravó aún más el cuadro, con ataques violentos a los derechos, a la democracia y sus instituciones y a las políticas sociales y culturales. Negación de la ciencia; destrucción del medioambiente; políticas de exterminio de indígenas; demonización del arte, de la cultura y de la educación, bajo la acusación de "comunismo" y de inducir conceptos y prácticas que desentonaran con un patrón moral conservador; intolerancia política; ataques sistemáticos a las instituciones democráticas; y proliferación deliberada y criminal de noticias falsas son algunos de los elementos marcantes de las políticas del actual gobierno federal.

Los resultados desfavorables de las fuerzas progresistas en las elecciones municipales de 2016, implicaron la elección de muchos secretarios municipales de salud desvinculados de la histórica experiencia de construcción del SUS. Como agravante, los modos de hacer política y de efectivizar las relaciones interfederativas contribuyeron a un vaciamiento del debate en torno a las políticas de salud y a la cristalización de relaciones de subordinación entre las entidades federadas ${ }^{(12,13)}$.

El singular diseño federativo brasileño cuenta con tres esferas: unión, estados y municipios y, en el SUS, constitucionalmente, la gestión de cada ente federado es autónoma. Políticamente, en el proceso de conformación del SUS, se instituyó un modo tripartito de producir políticas, que incluyó la creación de instancias de intergestión en el ámbito nacional, estadual y regional, de modo que, a pesar de las singularidades y de la autonomía local sea posible una acción articulada y una unidad de principios al efectivizar las políticas y operar el sistema de salud. Además, existen también instancias de participación social, que incluyen gestores, trabajadores y usuarios.

Sin embargo, a pesar de todo este acuerdo democrático y de que la descentralización sea uno de los principios del SUS, se fueron consolidando relaciones de subordinación, del Ministerio de la Salud sobre las secretarias estaduales y municipales y de las secretarías estaduales sobre las secretarias municipales, desde una lógica en la cual la mayor capacidad de financiamiento del Ministerio de la Salud fue utilizada como estrategia de poder, basada en una "inducción" financiera de las políticas, que atropelló, en gran medida, el debate político ${ }^{(12,13)}$.

Así, la oferta de nuevos recursos para financiar las acciones y servicios de salud quedó cada vez más condicionada a la adhesión a las formulaciones políticas y propuestas de acuerdo asistencial del Ministerio de Salud ${ }^{(9)}$.

Es posible enumerar varios efectos de la adopción de esas políticas de "inducción". Primero, una tendencia sostenida a lo largo de los años y de los gobiernos de, a partir de las políticas nacionales, estandarizar los modos organizativos de la atención sin considerar los contextos y la acumulación local, restringiendo la expresión de la creatividad y las necesidades de los municipios ${ }^{(9)}$.

Segundo, hubo una subordinación del debate político a los mecanismos de financiamiento, que contaminaron la formulación de políticas, principios y directrices con las lógicas de financiamiento y racionalización de gastos.

Estos dos efectos contribuyeron a configurar una relación de subordinación entre los entes federados (manda más quien tiene más dinero), perversa para los municipios, considerando, especialmente, el déficit de financiamiento crónico al que está sometido el SUS desde su creación. También contribuyeron al no fortalecimiento y al debilitamiento del potencial de formulación política de las gestiones municipales (muy activas y propositivas en el inicio del SUS) e inauguraron una práctica de sobrevalorización de las declaraciones formales del supuesto deber ser del SUS, sin el reconocimiento y la discusión de los procesos vivos de construcción que se multiplican por el país ${ }^{(9)}$.

Además, a pesar de que la participación democrática de los ciudadanos en la construcción de las políticas esté formalmente instituida en el SUS (por medio de los consejos y de las conferencias de salud), a lo largo 
de los años, hubo crisis en esos acuerdos y espacios. Crisis por ser espacios que suponen representación y que no fueron sintonizados con las nuevas dinámicas más fluidas y fugaces de los movimientos sociales. Crisis porque su agenda se apartó de la producción viva de la salud y fue capturada por aspectos tecnicistas y formales de la construcción del SUS. Crisis porque se amplió el papel fiscalizador y se vació su papel activo en la formulación de las políticas de salud. Crisis porque se debilitó la apuesta por una gestión democrática del sistema de salud ${ }^{(14)}$.

Todo esto implicó una ampliación del protagonismo de los gestores del sistema de salud, tanto en la definición de las políticas, como en las dinámicas de operación del sistema, incluyendo las lógicas de organización del trabajo en salud.

\section{Tercerización de la gestión en salud}

Otro elemento que ha interferido fuertemente en la dinámica de la gestión y el trabajo en salud es un movimiento creciente de tercerización de la gestión de servicios de salud, de los estados y municipios hacia organizaciones sociales (entes privados no lucrativos). Esas organizaciones asumen la gestión de los servicios públicos y del trabajo mediante contratos de gestión, según los cuales los estados y los municipios les transfieren, a estas organizaciones, recursos y responsabilidades directas en la prestación de los servicios de salud $^{(15)}$.

Ese movimiento de tercerización de la gestión está asociado a las tendencias de desmantelamiento del Estado y restricción de los derechos sociales que se expresa, entre otras formas, en una Ley de Responsabilidad Fiscal $^{(16)}$ (instituida en 1997, en el gobierno Fernando Henrique, y nunca revocada), que impone un techo bastante draconiano a los gastos públicos para la contratación de personal en el área de salud y de educación. Esa restricción afectaría directamente la capacidad de contratar personal de los entes federados, lo que restringiría las posibilidades de expansión de los servicios. Sin embargo, ese techo no se aplica a las personas jurídicas, por lo que a través de las organizaciones sociales tercerizan la contratación del personal para los servicios. Esta modalidad se ha constituido en una maniobra para sustentar la expansión y diversificación de los servicios de salud en el SUS, a pesar de la responsabilidad fiscal, desde fines de la década de 1990 hasta la fecha, pero cargando el peso de la incorporación de lógicas de lo privado en la gestión del trabajo en salud.

Además, incluso durante los gobiernos progresistas, aunque existían propuestas de dispositivos en la dirección opuesta, que favorecían las producciones compartidas, las prácticas de salud se construían más desde una perspectiva medicalizante de la vida de los usuarios. En la atención básica, esa apuesta de gobierno de medicalización de la vida del otro ha sido más fuerte que en la salud mental.

La salud surgió como tema político en el proceso de constitución del Estado moderno: gobernar la vida, gobernar la ocupación del espacio de las ciudades, y producir como valores el trabajo, la familia, la higiene para generar cuerpos dóciles para la producción. Esa es una discusión conocida. Pero ante esa fuerza disciplinadora, se produce un pliegue que se expresa en el tensionamiento de la agenda de salud por parte de los movimientos sociales, quienes plantean la lucha por la salud como derecho. Esa tensión se expresa, entre otros elementos, en el tema del gobierno de la vida, que atraviesa el trabajo y la agenda de salud.

La política de salud mental antimanicomial entiende que en las vidas que se cuidan, más que una persona portadora de un diagnóstico, existe una persona ciudadana. Que esas personas ciudadanas recobren autonomía en el gobierno de su propia vida es una de las apuestas del cuidado en libertad. Es una tensa disputa con el modelo biologicista-manicomial, que reduce las existencias a los diagnósticos e interroga sus posibilidades de autogobierno y de convivencia social. Disputa intensa, pero hay disputa. Hubo y hay apuestas a la construcción compartida y singular de proyectos terapéuticos a partir de 
lo que tiene sentido para los usuarios, más allá de la prescripción medicamentosa, ampliando sus territorios existenciales ${ }^{(17,18)}$.

En la atención básica, a partir de una mirada reduccionista y biomedicalizada, la vida en el territorio muchas veces se reduce a diagnósticos tomados como problemas prioritarios de salud; la vida de los usuarios se define en torno al control de esos problemas-diagnóstico (hipertensión, diabetes, tuberculosis, etc.); los proyectos terapéuticos son mayoritariamente unilaterales, centrados en el uso de medicamentos y en prescripciones de los modos de andar la vida; y el principal reclamo de las y los trabajadores tiene que ver con la "no adhesión" de las personas usuarias "a los tratamientos". Entonces, a pesar de que haya una disputa de proyectos terapéuticos de la vida en el territorio, algunas veces, al entrar en las unidades predomina la apuesta de gobernar la vida de las personas usuarias ${ }^{(19,20)}$.

Todos esos elementos han contribuido a la progresiva adopción de dispositivos de control, de reclusión del trabajo vivo, de endurecimiento de la gestión, de empobrecimiento de los encuentros entre trabajadores y entre trabajadores y personas usuarias que se dan en las prácticas de salud. Sufrimiento de trabajadores, sufrimiento de usuarios y de usuarias. Sin embargo, aun así hay líneas de fuga, aun así se producen encuentros potentes, aun así existe un compromiso por el cuidado en el territorio ${ }^{(19)}$. Y, en esa coyuntura, llega el COVID-19.

\section{El enfrentamiento del COVID-19 en el ámbito federal}

El negacionismo del gobierno federal imposibilitó llevar a cabo estrategias de distanciamiento social y no hubo, por parte de ninguna esfera del gobierno, políticas abarcativas para proteger al conjunto de la población. Enfrentar la pandemia es una agenda política, económica y social, que exige respuestas amplias y articuladas, que no hubo. Resultado: responsabilización individual de la prevención, se aisló quien estaba de acuerdo con esa estrategia de prevención y podía aislarse. Quien tenía que salir a trabajar o a pelear el sustento, quedó expuesto. El Congreso Nacional instituyó una ayuda financiera de emergencia, que demoró y fue irregular, pero evitó una catástrofe más grave en 2020, pero no en $2021^{(3)}$.

Por primera vez en la historia del SUS, hubo una desarticulación total entre los entes federados para enfrentar un grave problema sanitario. El Supremo Tribunal Federal reafirmó la complementariedad de las responsabilidades y la autonomía de los estados y municipios para adoptar medidas de protección a la salud de sus poblaciones, en contraposición al desatino explícito del gobierno federal.

En Brasil, como en muchos lugares del mundo, prevaleció una respuesta biomédicocentrada en la pandemia. El tema central del COVID-19 era el encuentro del virus con los cuerpos, la inversión en hospitales, camas de terapia intensiva, respiradores. La vigilancia epidemiológica servía solo para contar casos y muertes, perdiendo su protagonismo en detectar casos y aislarlos ${ }^{(3)}$.

En este artículo, partimos de la respuesta viva de la población y de las y los trabajadores, para mapear procesos de subjetivación vividos y recopilados en nuestro grupo de investigación, como ya fue mencionado, para ampliar un debate sobre trabajo en salud y subjetividad.

\section{SENTIMIENTOS Y REACCIONES A LA PANDEMIA: TENSIONES Y PROCESOS DE SUBJETIVACIÓN}

\section{Miedo y espanto generalizados}

En la red básica, en un inicio, los trabajadores se recluyeron. El trabajo fue reorganizado para atender sintomáticos respiratorios, y el resto quedó rápidamente en suspenso.

La pandemia demoró un tiempo (dos meses) en llegar a las periferias y al interior. Sin embargo, se suspendieron simultáneamente todas las actividades en todos lados. De a poco, las y los trabajadores de la atención básica comenzaron a reorganizar los cuidados de las personas usuarias con enfermedades 
crónicas, con tuberculosis, con deficiencias, de los cuidados prenatales en mujeres, etc. ${ }^{(3)}$.

Tres semanas después de las primeras medidas radicales de suspensión de las actividades económicas adoptadas por el gobierno estadual, comenzaron a circular en Internet problematizaciones y reflexiones acerca del papel que la atención básica podría cumplir en el cuidado de la población. Al tener la más amplia capilaridad dentro del SUS, la atención básica podría hacer muchas cosas, dada su aproximación a las realidades territoriales. El canal de Youtube TV Rede Unida dio el puntapié inicial a ese debate con algunos vídeos que tuvieron bastante impacto ${ }^{(21,22)}$.

Fue una provocación desde afuera hacia dentro del SUS o, mejor dicho, desde las márgenes del SUS hacia la gestión formal del sistema. El debate se encendió, los videos se viralizaron. En menos de dos semanas, discusiones y propuestas se multiplicaron y se propagaron por todo país. El primer aprendizaje fue, entonces, desplazar a una subjetividad subordinada, temerosa y obediente: a pesar del silencio de las esferas gestoras del SUS, frente a una invitación que llegó a la red, muchos equipos se cuestionaron y se pusieron en movimiento. ¡Podemos!

De un modo heterogéneo, en muchas ciudades los equipos comenzaron a sumergirse en el territorio y se encontraron con muchas cosas. Con movimientos sociales y colectivos de la población que ante la necropolítica gubernamental explícita respondieron: nos quieren matar, pero decidimos vivir. Con prácticas solidarias de diversos tipos: dinero, alimentos, productos de limpieza e higiene, movimientos de autoorganización para cuidar la salud, para producir barbijos para todos. Fue una sorpresa para algunos equipos que, acostumbrados a colocarse en el lugar de prescribir y gobernar la vida de la gente, muchas veces no sabían qué hacer ante tanto protagonismo colectivo. Otros, se comprometían y fortalecieron los movimientos territoriales existentes ${ }^{(23)}$.

Hubo también lugares en los que la organización propia de la comunidad no era tan fuerte y los equipos asumieron un protagonismo en las acciones de solidaridad. $\mathrm{Y}$ otros, en los que, ante el tsunami, muchos se ahogaban: la ciudadanía, las y los trabajadores, la gestión, por lo que la población quedó abandonada a su propia suerte, con una limitada articulación y con bajas posibilidades de generar solidaridad, con equipos ausentes, guardados en las unidades de atención.

De un modo general, entre los equipos públicos, solo los de salud estaban en el territorio. Los otros servicios estaban todos en cuarentena. Mucho ánimo, mucha invención en esos encuentros. Trabajo vivo en acto. Se producían nuevos sentidos en el trabajo en salud. “¡Para esto deberíamos existir! ¡Encontrarnos con la vida y producir vida!"

Los equipos más sensibles rápidamente percibieron que las recomendaciones "quédate en casa, usa máscara y lávate las manos" no encajaban en la vida de muchos segmentos de la población. Casas pequeñas con mucha gente. Gente que tenía que salir a trabajar para sobrevivir. A veces faltaba el agua por la inestabilidad en la provisión del servicio. Necesidad de crear acuerdos y rabia por la indiferencia de las autoridades. Situación compleja por demás. Ampliar la porosidad para acercarse a los colectivos y diferentes grupos territoriales. Crear nuevas agendas, trabajo vivo en acto, encuentro, aperturas, interrogantes, invenciones ${ }^{(23,24)}$.

Otros equipos, no. Partían del supuesto de que si la población no se quedaba en casa era porque no entendía las instrucciones. Había que repetir las instrucciones. Repetir, repetir... No consideraban otras hipótesis explicativas que "no entendieron" o "no se quieren cuidar". Subjetivación subordinadora, autoridad instituida e incuestionable con base en el saber de la ciencia.

Pero ¿qué saber? La pandemia nos obligó colectivamente a asumir no saber. Un virus nuevo, desconocido, sin remedio ni vacuna. Este fue un elemento bastante desestabilizador para gestores y trabajadores de la salud, que se encontraron con el no saber y muchas veces no supieron lidiar con eso ${ }^{(25)}$.

Los equipos gestores no discutían claramente sus dudas e inseguridades, absolutamente esperadas ante la coyuntura de la pandemia y en un contexto político complejo, 
en que los mecanismos del SUS para conversar y producir acuerdos compartidos no funcionaron. Sin embargo, admitir incertezas no forma parte del repertorio del modo hegemónico de "ser gobierno". Subjetivación subordinadora, basada en saberes cristalizados, que se desestabilizó con la explicitación de lo imprevisible y lo desconocido.

Trabajadores que se irritaban con la gestión "que no sabía", y buscaban certezas que no existían. Gestores que esperaban una "tropa unida" cuando no había tropa, y mucho menos certezas para una unión, que tampoco se estaba construyendo. Entonces, se generó mucha inseguridad y acusaciones mutuas ${ }^{(25)}$.

La incertidumbre y los imprevistos forman parte del cotidiano del trabajo en salud, pero no suelen ponerse en evidencia porque se consideran desestabilizadores, porque exigen trabajo vivo, reconocimiento del no saber, necesidad de reconocer límites, y producir intercambios $^{(26)}$. Requieren conversación abierta, construcción colectiva, y acogida de la novedad de la situación. Esa sería la producción indispensable para construir pactos, confianza, posibilidad de respirar ante de tanta tensión. Subjetivaciones subordinadas y subordinadoras no combinan con el diálogo franco, no combinan con sustentar tensiones ${ }^{(26)}$.

Con el transcurso de los meses, se fueron creando espacios de conversación locales, municipales y regionales. El Consejo de Secretarios Municipales de Salud, estructuras regionales de la Secretaría Estadual, profesores universitarios, trabajadores de la gestión y de la atención, fueron muchas las formas de dar soporte a conversaciones y reflexiones. Más o menos potentes, pero comenzaron a existir.

De a poco, fue creciendo el reconocimiento de que no había que quedarse esperando "la orden que viene de arriba". O peor aún, "la orden que venía de arriba" muchas veces contradecía la producción viva del cuidado y de los encuentros territoriales. La invención y los cuerpos vivos se fueron activando, a pesar de las reglas vigentes de gobierno del trabajo, tanto en el SUS como en los espacios de las universidades, por ejemplo ${ }^{(26)}$.
¿La constatación de que "nos quieren matar, pero no nos vamos a morir" valdría solo para la población indígena, pobre, negra y periférica que se insubordina en defensa de su propia existencia? ¿O una derivación de esa disposición de lucha puede pertenecer también a los trabajadores de la salud?

\section{SALUD, TRABAJO EN SALUD Y PROCESOS DE SUBJETIVACIÓN}

En la salud como campo político, como ya fue mencionado, se produce un pliegue, por lo que coexisten la producción de procesos de subjetivación subordinada (en la línea del disciplinamiento y del control sobre la producción de la vida por parte del Estado, por el capital, por el saber oficial), por un lado, con la producción de procesos de cuidado que, en alguna medida, expanden las posibilidades del vivir (como expresión de las producciones autónomas de distintos grupos/ colectivos y de las luchas colectivas en torno a las políticas de existencias), por otro. Ese pliegue también incluye a quienes reivindican la salud como derecho, que es un efecto de captura, pero que se conecta y da lugar a la producción de vida ${ }^{(27)}$. Sin embargo, como señala Krenak, están también los que consideran que la salud es un modo de estar en el mundo y no un derecho ${ }^{(28)}$.

Ese pliegue implica una tensión constitutiva, implica disputas en torno del gobierno de la vida (de sí y del otro), que implica negacionismos de diversos órdenes: no solo el negacionismo contemporáneo, asociado al divorcio entre el conglomerado derecha política - sectores religiosos - capital financiero versus la ciencia, sino el negacionismo inmerso en la propia afirmación de la ciencia como única productora de discursos de verdad, que implicó históricamente la exclusión de la validez de todos los otros saberes.

La salud, entonces, es un campo de fuerzas constituido por la ciencia, por los modos de producción económica, por los modos de producción de vida, por los sentidos de la vida, que varían históricamente. Campo de 
fuerzas, de múltiples fuerzas, porque donde una fuerza actúa en un sentido, siempre hay otra que opera resistencia y, en general, hay campos de fuerza, varias fuerzas en tensión, no solo una contra otra ${ }^{(19)}$.

El trabajo en salud, se produce y se consume al mismo tiempo, pero de forma distinta a otras acciones de prestación de servicios, puede ser afectado y modificado por ambas partes, por eso se da en acto. Cuanto más se vea afectado por la singularidad del encuentro, cuanto mayor sea la porosidad de las dos partes para el encuentro, cuanto mayor sea la afectación mutua, más vivo será el trabajo en salud y más sentido puede tener su producto para ambas partes. Cuanto más definido esté a priori (por protocolos, preconceptos que llevan a la impermeabilidad o a la deslegitimación del usuario, de sus agendas y saberes, por ejemplo) y menos afectado por el encuentro, mayor será el predominio del trabajo muerto y habrá menores chances de que el producto movilice, tenga sentido, se produzcan efectos que potencien la vida. A pesar de eso, el predominio del trabajo muerto en esas situaciones no impide que ocurran efectos sobre ambas partes ${ }^{(19)}$.

Justamente, al estar marcado por el pliegue constitutivo de la salud, con diferentes planos de disputas que afectan las partes involucradas en su producción, el trabajo en salud es una rica superficie de afectación y de procesos de subjetivación que demandan conversar, preguntar sobre lo vivido, experimentar, recoger efectos, autocuestionarse. Pliegues y disputas que implican relaciones de poder y producción de visibilidades e invisibilidades, que producen múltiples y variados agenciamientos, simpatía, compasión, irritación, reconocimiento, desprecio, negación, posibilidades e imposibilidades de composición, sufrimiento, afirmación de autoridad, reconocimiento del no saber, angustias de diferentes tipos. A no ser para quien invisibiliza totalmente al otro -a partir de la afirmación unilateral y absoluta del saber técnico-científico- son pliegues y disputas que incomodan, producen incertidumbre, no saberes, angustias ${ }^{(3)}$.
Una Secretaría de Salud, un espacio de gestión central o cualquier unidad de salud, se producen en diferentes planos. Hay un plano formal, del deber ser, que lo definen las políticas de salud (nacionales, estaduales, municipales) y/o la empresa propietaria y gestora, en el caso de los servicios privados y/o públicos bajo gestión privada. Finalidad, papeles, protocolos, flujos. Pero hay muchos otros planos que interfieren en esa producción y atraviesan ese plano formal ${ }^{(30)}$ : los condicionamientos políticos y materiales que dificultan o facilitan procesos y operaciones; la historia del lugar; la mayor o menor presencia del sector privado; las presiones locales; las perspectivas y disputas entre las corporaciones profesionales, las perspectivas de los movimientos sociales; y también aspectos relacionados con las historias de vida de gestores, trabajadores y usuarios, sus convicciones, proyectos ético-políticos y relaciones entre trabajadores. Todos esos planos modifican y modulan ese plano formal, abriendo y cerrando posibilidades ${ }^{(30)}$.

Así, a pesar de que existan ciertas regularidades entre secretarías y servicios de salud, también hay diferencias derivadas de las distintas combinaciones y entrecruzamientos entre estos y otros planos de constitución, que son también expresión de campos de fuerza que atraviesan el trabajo en salud y los procesos de subjetivación.

Es importante señalar que las fuerzas no son abstractas, se instauran en los procesos relacionales, en el campo de la micropolítica, dado que fuera de esa constitutividad no existen. En el caso de la salud, en los encuentros, en las relaciones entre gestores y trabajadores; entre trabajadores; y entre gestores, trabajadores y usuarios se instauran los campos de fuerza que conforman modos de estar en el encuentro, constituyendo procesos de subjetivación ${ }^{(29)}$.

¿Qué son los procesos de subjetivación? Son esos procesos continuos de tensionamiento (producidos por las fuerzas en disputa) que conforman las personas en su vida cotidiana. Por eso preferimos discutir procesos de subjetivación y no subjetividades. 
Los procesos de subjetivación son móviles, mutables, situacionales, siempre relacionales y en disputa. La subjetivación no es fija, está en producción. Se moviliza y está atravesada por vectores más o menos estructurados, más permanentes o más volátiles, que afirman o cuestionan espacios de poder, explicitan endurecimientos o desconstrucciones, o endurecimientos y desconstrucciones. Como ya fue mencionado, la formación profesional, las disputas corporativas, las historias de vida, los proyectos ético-políticos, los agenciamientos producidos por las políticas, las lógicas de gestión, los efectos de la convivencia en equipo, los conceptos de salud, los encuentros individuales y colectivos con los usuarios, los agenciamientos colectivos del miedo y de la solidaridad, son muchos planos, vectores y producciones. Los procesos de subjetivación marcan el trabajo en salud y también están influenciados por él ${ }^{(30)}$.

El mismo equipo que cuida en una situación, excluye al usuario en otra. El mismo trabajador que no escucha a nadie, en otro escenario se moviliza intensamente y motiva a la producción compartida del cuidado. Aunque las molaridades políticas, organizacionales y existenciales produzcan regularidades, hay mucha variación e invención. Las y los trabajadores se sienten oprimidos, sin elección, limitados, pero también oprimen, limitan, restringen. $Y$, en otros momentos, inventan, conforman, se escapan y construyen complicidades y reconocimientos.

Esta variabilidad atrae y asusta. El cartesianismo que llevamos dentro valora la estabilidad, lo previsible, lo que puede ser establecido. Al mismo tiempo que el trabajo vivo atrae -porque produce sentidos y posibilita la invención-, asusta, porque explicita que no hay respuestas para todo y por poner en evidencia la responsabilidad de cada uno y de todos por los actos y acciones del cuidado y de la salud.

El trabajo vivo, que habita el trabajo en salud de un modo constitutivo por el hecho de que se da en el encuentro y es afectado por los participantes, confiere a los gestores, trabajadores y usuarios un grado de libertad que es indispensable para el cuidado en salud, dado que, en el marco del encuentro, posibilita el reconocimiento de las singularidades y la producción compartida. Por eso, en salud, en mayor o menor grado, con mayor o menor gobernabilidad, todos -incluso los usuarios- gestionan, disputan el gobierno de sí y de los otros.

Hay modos menos democráticos y más verticales de gestión que agencian el empobrecimiento del trabajo, no solo en función del gerencialismo, sino también en función de la pretensión (inútil) del control absoluto, del gobierno total sobre el otro. Son agenciadores de subordinación, lo que, por otro lado, implica no hacerse responsable -"yo no decido, las reglas no lo permiten, no puedo hacer nada" - y un cierto grado de comodidad de las y los trabajadores que, al mismo tiempo, se indignan con las reglas restrictivas o que claramente no dan respuestas a todas las situaciones. Las y los trabajadores también producen modos subordinados. Es una producción activa, no solo un efecto.

Pero las y los trabajadores también disputan, no solo obedecen. Disputan y ejercitan el trabajo vivo, y cuidan de la forma que tiene más sentido o es más cómoda. La insubordinación no necesariamente es para el bien...

Modos menos democráticos y más rígidos en la producción de los actos de salud, en el encuentro con los usuarios, prescriben, no admiten la pregunta, buscan el gobierno de la vida de los usuarios según criterios técnicos, juicios morales. Buscan ser subordinadores ante usuarios que disputan proyectos de cuidado, porque la prescripción recibida no encaja en su vida, porque sus preguntas no fueron escuchadas, sus preocupaciones y valores no fueron consideradas y se insubordinan.

En la pandemia de COVID-19 hubo procesos de subjetivación subordinadores, subordinados, insubordinados por todos lados. Los gobiernos estaduales entraron en el juego a causa de la omisión criminal del gobierno federal, pero de modo centralizador. Los gobiernos municipales tuvieron que disputar sentidos y soluciones, sufriendo presiones locales de todo tipo, sin el necesario apoyo 
político que los procesos de concertación serían capaces de producir. La red básica entró en el juego de la pandemia sin ser agenciada por la esfera estadual del SUS y a veces sin ser agenciada por la misma esfera municipal. Un juego tenso de responsabilización-desresponsabilización en la producción de muerte y en la producción de vida.

Hubo trabajadores agenciados por la vida en el territorio, interrogados por la incertidumbre, movilizados por el encuentro con usuarios sorprendentemente activos y que en forma colectiva ejercitaron su autogobierno para producir vida. Hubo trabajadores que mantuvieron la pretensión de gobernar la vida de los usuarios, repitiendo mecánicamente instrucciones -incluso cuando obviamente no servían- y culpabilizando a los usuarios por la expansión de la pandemia.

Los movimientos sociales entraron y salieron de la escena, fueron protagonistas de la solidaridad, el cuidado y de nuevos debates en defensa de la vida. Dejaron en evidencia la des-sintonía de los cuidados ofrecidos con sus deseos, necesidades y referencias.

Pero hubo segmentos sociales que se asociaron a la política genocida del gobierno federal. Se insubordinaron a las políticas de defensa y protección de la vida, y protagonizaron la necropolítica.

\section{PROCESOS DE SUBJETIVACIÓN, APRENDIZAJES Y ALGUNAS CONSIDERACIONES A MODO DE CIERRE}

Todos aprenden de la experiencia. Todas las personas aprenden a través de la experiencia porque el mundo es una escuela. Es una cuestión de vida o muerte, o de vida y muerte. Hasta una ameba en su encuentro con el ambiente aprende y se modifica, como resalta Maturana ${ }^{(31)}$.

Entonces, en diferentes composiciones, con y sin autorización, con y sin apoyo, en espacios informales y formales, trabajadores y usuarios aprenden en el trabajo en salud todo el tiempo, porque el trabajo en salud se hace en el encuentro y en la experimentación. En Brasil, esto se tornó un tema de política, de política de salud.

En realidad, hace mucho tiempo que es un tema de política porque la apuesta a la conformación de subjetividades por medio de procesos formativos ha sido adoptada como parte de los dispositivos efectores de las políticas de salud: las famosas capacitaciones.

Cada política nueva, una nueva ola de capacitaciones para ajustar las prácticas de salud a los "nuevos" saberes técnicos y orientaciones políticas. Efectos limitados, claro, porque no son solo los saberes técnicos que orientan las prácticas de salud y tampoco basta la presentación de nuevas informaciones y nuevos protocolos para que gestores y trabajadores "se adecuen"(12).

Sin embargo, más allá de las diferencias entre educación permanente y educación continua, tema que muchos autores en el Brasil resaltan como la principal tensión en los debates de las políticas de educación en salud $^{(32,33)}$, es decisivo problematizar justamente los dispositivos de subjetivación movilizados, ya que explícitamente cualquier tipo de educación pone el tema sobre la mesa.

Se puede invitar a pensar sobre lo vivido, convocar a todas las personas a pensar sobre lo vivido, pensar colectivamente. Lo vivido no reducido a lo visibilizado en los procesos de padecimiento, no solo como lo que sucede en el ámbito o por iniciativa de los servicios de salud. Pensar colectivamente sobre lo vivido en la producción de las existencias en toda su diversidad y complejidad. Invitar a los segmentos más diversos a ponerse en movimiento, a proponer la producción de lo común. Invitación que se modifica y se amplía, que no tiene dueño. Invitación sustentada en diferentes espacios, sobre todo en los espacios locales y en el cotidiano ${ }^{(34,35)}$.

O puede ponerse el énfasis en el moldeado, en la capacitación, reafirmando las capacitaciones como dispositivo para efectivizar las más variadas políticas de salud. Conocimiento técnico como prescripción de prácticas y relaciones. Moldear subjetividades a partir de formaciones. 
Es importante considerar que si el trabajo es vivo y las tensiones son permanentes, si los planos que atraviesan el trabajo son múltiples, si el cuidado se produce en el encuentro y es afectado por las partes que se encuentran, incluso en el caso de que exista una linda y perfecta formación previa, todavía sería necesario pensar sobre lo vivido, recoger efectos, construir desde la singularidad de las experiencias y de los contextos. No hay formación que elimine las diferencias, las disputas. No hay formación que agote los agenciamientos y tensiones de los encuentros y de los imprevistos. No hay construcción definitiva. No hay subjetividades listas y fijas (incluso cuando las políticas y la gestión apuestan a una captura del trabajo vivo y al control de su efectuación), hay procesos de subjetivación, en movimiento, en producción.

Además, el trabajo compartido, en equipo o en red, no se produce a partir de la prescripción. Se produce a partir de la construcción de sentidos comunes, del reconocimiento de que crear juntos vale la pena, amplía posibilidades, a pesar de las tensiones, diferencias y disputas en cada momento ${ }^{(21)}$. Y la experiencia de enfrentar el COVID-19 también sirvió para eso. En la atención básica, se propició la construcción de comunes. Los equipos y las diversas profesiones nunca estuvieron tan articulados como en este momento. $Y$, en muchos lugares, quienes fueron llamados a cuidar en red también cobraron fuerza, produciendo nuevos sentidos sobre el trabajo.

Nadie lo prescribió. Fue la fuerza de la vida quien Ilamó. Por eso, con relación a aprender de la experiencia, cabe el reconocimiento y no la prescripción.

Pero cabe también preguntarse qué voces y qué cuestionamientos se escucharon de la vida en el territorio. Cabe escuchar para ir más allá e interrogar en profundidad los sentidos de lo que se recogió y vivió.

Que tenga sentido para los usuarios es tan importante como que tenga sentido para los trabajadores. Del mismo modo que entre los trabajadores existen muchos proyectos en disputa, no existe una homogeneidad entre territorios, poblaciones y usuarios. Los modos colectivos de producir la vida, muy intensos en ciertos territorios, cuestionan el sentido de "casa", en el "quedarse en casa". Tal vez, más allá de los problemas materiales para hacer efectivo el distanciamiento social, este sea un punto crítico: el sentido de casa puede no ser el mismo, pues compartir intensamente y casi de forma permanente el vivir puede ser mucho más crítico (en el sentido de vital) para los que experimentan ciertas "comunidades" (nuevas comunidades, nuevos modos colectivos) en el modo de organizar la vida. Una comunidad solidaria que persiste y que se inventa y es potencia, a pesar de que esas vidas también estén atravesadas por los procesos de individualización y competición del humano-empresario de sí del neoliberalismo.

Modos colectivos que se expresan de formas distintas. Colectivos negros, múltiples colectivos culturales, colectivos de género. Diferentes religiosidades, que producen diferentes agrupaciones y tensiones. El territorio, entonces, está lejos de ser homogéneo, a pesar de que la precariedad sea común, precariedad de las viviendas, del trabajo, de los medios de transporte, de las escuelas, de las áreas de tiempo libre. Diferentes colectivos inventan distintos modos de resistir, de producir sentidos que interrogan incluso, de diferentes modos, las verdades del sector salud que se esfuerza por gobernar sus vidas.

Diferentes subjetivaciones, valores en disputa, distintos modos de cuidar de sí, individual y colectivamente. Eso cambia todo en el modo de aproximarse, en el modo de conversar, en la posibilidad de composición. Interroga profundamente el modo predominante del pensamiento en salud, incluso el de la salud colectiva.

Son interlocutores válidos, todos, unos más explícitamente rebeldes que otros, unos más articulados que otros, otros francamente conservadores. Muchos en conflicto abierto entre sí. Son portadores de nuevas agendas, productores de otros cuidados, mundos otros con los que las y los trabajadores de salud necesitan encontrarse y dialogar. Están muy lejos de la imagen de personas que "necesitan ser educadas" según lógicas que la salud/ 
ciencia oficial prescribe y que buscan responsabilizarlas individualmente por la producción de su salud.

Estos son cuestionamientos importantes. Durante la pandemia, hubo acuerdos y conflictos, y nos cabe aprender de todo lo vivido y sostener los interrogantes para acumular la potencia para la insubordinación indispensable de las y los trabajadores de la salud, en conjunto $-y$ no en lucha- con los usuarios. Esa interrogación compartida es el camino para producir otras subjetivaciones, productoras de potencia, que deberían ser el único criterio de evaluación de las políticas y de las prácticas de salud, que reconozcan la ampliación de la potencia de vida como el criterio para evaluar políticas y prácticas, y escapen así de los juicios morales o instrumentales ${ }^{(36)}$.

"No nos van a apresar" es agenciamiento que vale para todos los que, tanto en el SUS, como en las instituciones de enseñanza, están comprometidos con la defensa de la vida y no se dejan capturar por las reglas, protocolos, metas, productivismo, que esterilizan el trabajo, roban su vida, aniquilan compromisos ético-políticos. La pandemia intensificó las posibilidades de experimentación, abrió nuevas posibilidades de conexión, posibilitó respirar libertad, a pesar de toda tensión y sufrimiento. ¡La insubordinación por la vida puede ser agenciamiento colectivo en el mundo del trabajo en composición con los muchos mundos de la vida!

Y necesitamos esa potencia acumulada, esos aprendizajes, para renovar convocatorias y agenciamientos para resistir y producir vida. Para hacer política de otros modos, más colectivos e insubordinados. Necesitamos mucho porque ahora estamos cansados, extenuados, agotados ante el espectáculo tenebroso de la necropolítica que provoca la muerte o deja morir a 3.000 brasileños al día por la pandemia de COVID-19 en el momento que cierro este artículo.

\section{REFERENCIAS BIBLIOGRÁFICAS}

1. Merhy E. Educação permanente em movimento - uma política de reconhecimento e cooperação, ativando os encontros do cotidiano no mundo do trabalho em saúde, questões para os gestores, trabalhadores e quem mais quiser se ver nisso. Saúde em Redes. 2015;1(1):7-14.

2. Feuerwerker LCM. Educação Permanente em Saúde: educação, saúde, gestão e produção do cuidado. Micropolítica e saúde: produção do cuidado, gestão e formação. Porto Alegre: Rede Unida; 2014. p. 89-104.

3. Seixas CT, MerhyEE, Feuerwerker LCM, Santo TBE, Slomp Junior H, Cruz KT. A crise como potência: os cuidados de proximidade e a epidemia pela COVID-19. Interface - Comunicação, Saúde, Educação. 2021;25(Supl.1):e200379.

4. Cecilio LC, Merhy EE, Campos GWS. Inventando a mudança na saúde. São Paulo: Hucitec; 1997.

5. Borges CF, Baptista TW, Mattos RA. Um ensaio sobre a ideia de reforma sanitária brasileira. En: Guizardi FL, Nespoli G, Cunha MLS, Machado F, Lopes M, org. Políticas de participação e saúde. Rio de Janeiro: EPSJV; 2014. p. $37-58$

6. Brasil, Presidência da República. Emenda Constitucional 95 [Internet]. 2016 [citado 16 dic 2020]. Disponible en: https://tinyurl.com/8jazry6j. 
7. Funcia RF. Estimativas da perda de recurso de Sistema Único de Saúde (SUS) como decorrência da Emenda Constitucional 95/2016. Domingueira da Saúde [Internet]. 2020 [citado 12 mar 2021]. Disponible en: https://tinyurl.com/8x8xmchp.

8. Santos L. Desvincular receitas que garantem o mínimo na saúde e na educação é inconstitucional. Domingueira da Saúde [Internet]. 2021 [citado 12 mar 2021]. Disponible en: https://tinyurl.com/h7357zhz.

9. Feuerwerker LCM. Da atenção básica à atenção primária - do cuidado integral territorializado à focalização médico-centrada no SUS: AMAQ, PMAQ e remuneração por resultados. En: Akerman M, Sanine PR, Caccia-Bava MC, Marim FG, Louvison M, Hirooka LB, Marques MC, org. Atenção básica é o caminho!: Desmontes, resistências e compromissos: contribuições das universidades brasileiras para avaliação e pesquisa na APS - perspectivas avaliação, pesquisa, cuidado em atenção primária à saúde. São Paulo: Hucitec; 2020, v. 2, p. 337-356.

10. Almeida JMC. Política de saúde mental no Brasil: o que está em jogo nas mudanças em curso. Cadernos de Saúde Pública. 2019;35(11):e00129519.

11. Morosini MVGC, Fonseca AF, Lima LD. Política nacional de Atenção Básica 2017: retrocessos e riscos para o Sistema Único de Saúde. Saúde em Debate. 2018;42(116):11-24.

12. Feuerwerker LCM. Micropolítica e saúde: produção do cuidado, gestão e formação. Porto Alegre: Editora Rede Unida; 2014.

13. Feuerwerker LCM. A produção do SUS como política: Os modos de fazer política marcando a produção do SUS. En: Merhy EE, Baduy RS, Seixas CT, Almeida DES, Júnior HS, org. Políticas e Cuidados em Saúde. Avaliação Compartilhada do cuidado em saúde: Surpreendendo o instituído nas redes. Vol 1. p. 73-76. Rio de Janeiro: Hexis Editora; 2016.

14. Guizardi FL, Nespoli G, Cunha MLS, Machado F, Lopes $M$, org. Políticas de participação e saúde. Rio de Janeiro: EPSJV; 2014.

15. Cegatti F, Carnut L, Mendes A. Terceirizações na área da saúde no Brasil: reflexos no SUS, nas políticas sociais e nos trabalhadores. Journal of Management \& Primary Health Care. 2020;12:e36.

16. Brasil, Senado Federal. Lei de Responsabilidade Fiscal: Lei Complementar No. 101, de 4 de maio de 2000 [Internet]. 2000 [citado 16 dic 2020]. Disponible en: https://tinyurl.com/htzxrxaw.

17. Santos HE, Amirat KM, Capozzolo AA, Siqueira PM, Martins LV, Santoro R, et al. Apagando incêndios: desafios do cotidiano do trabalho em saúde mental: um panorama de nossa vivência compartilhada numa RAPS em São Paulo. En: Merhy EE, Baduy RS, Seixas CT, Almeida DES, Júnior HS, org. Políticas e Cuidados em Saúde: Avaliação compartilhada do cuidado em saúde: Surpreendendo o instituído nas redes. Vol 1. Rio de Janeiro: Hexis Editora, 2016. p. 271-275.
18. Caron E, Feuerwerker LCM. A gam como dispositivo de atenção psicossocial nas práticas de apoio e cuidado compartilhado na atenção básica. En: Passos E, Sade C, Macerata I, org. Entre clínica e política: produção de conhecimento e cuidado em saúde. Rio de Janeiro: NAU Editora; 2020. p.353- 376.

19. Merhy EE, Feuerwerker LCM, Santos MLM, Bertussi DC, Baduy R. Rede Básica, campo de forças e micropolítica: Implicações para a gestão e o cuidado em saúde. Saúde em Debate. 2019;43(Spec 6):70-83.

20. Baduy RS, Kulpa S, Tallemberg C, Seixas CT, Cruz $\mathrm{KT}$, Slomp Junior $\mathrm{H}$, et al. "Mas ele não adere!": O desafio de acolher o outro no que é complexo para mim. En: Feuerwerker LCM, Bertussi DC, Merhy EE. Políticas e Cuidados em Saúde: Avaliação compartilhada do cuidado em saúde. Vol 2. Rio de Janeiro: Hexis, 2016. P. 220-227.

21. Feuerwerker LCM. Mobilizar potências dos territórios na luta contra a Covid-19. TV Rede Unida [Internet]. 6 abr 2020 [citado 10 nov 2020]. Disponible en: https://tinyurl.com/ba3pkwhn.

22. Merhy EE, Feuerwerker LCM, Pigatto F. Atenção Básica, Participação Comunitária, Covid-19. TV Rede Unida [Internet]. 18 abr 2020 [citado 16 dic 2020]. Disponible en: https://tinyurl.com/yfsftdxa.

23. XIV Congresso Internacional da Rede Unida. Praça 12 , cuidado de proximidade- eles querem nos matar e nós produzimos e inventamos para não morrer: Sinais que vem da rua [Internet]. 29 oct 2020 [citado 16 dic 2020]. Disponible en: https://tinyurl.com/28s8w6cr.

24. Feuerwerker LCM. Território: potências do cuidado. Curso de Micropolitica e Gestão da Atenção Básica [Internet]. 19 sep 2020 [citado 16 dic 2020]. Disponible en: https://youtu.be/g2k6fQcxj7Q.

25. Cosems SP, Feuerwerker LCM. Reflexões sobre a Saúde do Trabalhador no Contexto da Pandemia. Região de Araçatuba, São Paulo [Internet]. 16 sep 2020 [citado 16 dic 2020]. Disponível em: https://tinyurl.com/ y673ejjk.

26. SUS e Atenção Primaria da Saúde: O que aprendemos com a pandemia. Seminário USP [Internet]. 10 dic 2020 [citado 16 dic 2020]. Disponible en: https:// youtu.be/EMi9bIOK4vA.

27. Pelbart PP. Vida Capital: ensaios de biopolítica. São Paulo: Iluminuras; 2003.

28. Krenak A. Prefácio: Re-existir na diferença. Porto Alegre: Editora Rede Unida; 2020.

29. Feuerwerker LCM. Micropolítica e a formação de profissionais de saúde. En: Micropolítica em Saúde: produção do cuidado, gestão e formação. Porto Alegre: Editora Rede Unida; 2014. p.119-160.

30. Feuerwerker LCM. Pensando avaliação em políticas e na gestão em saúde numa perspectiva cartográfica construção compartilhada que favorece a mudança. En: Tanaka OY, Ribeiro EL, Almeida CAL, org. Avaliação em 
saúde: contribuições para incorporação no cotidiano. Rio de Janeiro: Atheneu; 2017. p. 29-36.

31. Maturana HR. Cognição, ciência e vida cotidiana. Belo Horizonte: UFMG; 2001.

32. Peres C, Silva RF, Barba PCSD. Desafios e potencialidades do processo de educação permanente em saúde. Trabalho, Educação e Saúde. 2016;14(3):783-801.

33. Campos KFC, Sena RR, Silva KL. Educação permanente nos serviços de saúde. Escola Anna Nery. 2017;21 (4):1-10.

34. Merhy EE. O desafio que a educação permanente tem em si: a pedagogia da implicação. Interface - Comunicação, Saúde e Educação. 2005;9(16):172-174.
35. Merhy EE, Feuerwerker LCM. Educação Permanente em Saúde: educação, saúde, gestão e produção do cuidado. En: Mandarino ACS, Gomberg E, org. Informar e Educar em Saúde: análises e experiências. Vol 1. Salvador: Editora da UFBA; 2011.

36. Moebus RN, Merhy EE, Silva E. O usuário-cidadão como guia: Como pode a onda elevar-se acima da montanha? En: Baduy RS, Seixas CT, Almeida DES, Slomp Júnior $\mathrm{H}$, org. Avaliação compartilhada do cuidado em saúde: surpreendendo o instituído nas redes. Rio de Janeiro: Hexis; 2016. p. 43-53.

\section{FORMA DE CITAR}

Feuerwerker LCM. Trabajo y subjetividad: reflexiones a partir de la experiencia de enfrentar el COVID-19 en el Sistema Único de Salud de Brasil. Salud Colectiva. 2021;17:e3356. doi: 10.18294/sc.2021.3356.

Recibido: 17 dic 2020 | Versión final: 17 mar 2021 | Aprobado: 25 mar 2021 | Publicado en línea: 15 may 2021

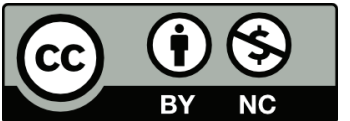

Esta obra está bajo una licencia de Creative Commons Reconocimiento-NoComercial 4.0 Internacional. Reconocimiento - Permite copiar, distribuir y comunicar públicamente la obra. A cambio, se debe reconocer y citar al autor original. No Comercial - Esta obra no puede ser utilizada con finalidades comerciales, a menos que se obtenga el permiso. 